\title{
Walking in the high-rise city: a Health Enhancement and Pedometer-determined Ambulatory (HEPA) program in Hong Kong
}

This article was published in the following Dove Press journal:

Clinical Interventions in Aging

18 August 2014

Number of times this article has been viewed

\author{
Angela YM Leung ${ }^{1,2}$ \\ Mike KT Cheung ${ }^{3}$ \\ Michael A Tse ${ }^{4}$ \\ Wai Chuen Shum ${ }^{5}$ \\ BJ Lancaster ${ }^{1,6}$ \\ Cindy LK Lam ${ }^{7}$
}

'School of Nursing, ${ }^{2}$ Research Centre on Heart, Brain, Hormone and Healthy Aging, Li Ka Shing Faculty of Medicine, University of Hong Kong, ${ }^{3}$ Centre on Research and Advocacy, Hong Kong Society for Rehabilitation, ${ }^{4}$ Institute of Human Performance, University of Hong Kong, ${ }^{5}$ Sheng Kung Hui Holy Carpenter Church Social Services, Hong Kong Special Administrative Region, People's Republic of China; ${ }^{6}$ School of Nursing, Vanderbilt University, Nashville, TN, USA; ${ }^{7}$ Department of Family Medicine and Primary Care, University of Hong Kong, Hong Kong Special Administrative Region, People's Republic of China

\footnotetext{
Corresponding author: Angela YM Leung Li Ka Shing Faculty of Medicine, University of Hong Kong, 4th Floor, William Mong Block, Faculty of Medicine Building, 2I Sassoon Road, Pokfulam, Hong Kong Special Administrative Region, People's Republic of China Tel +85239176630

Fax +85228726079

Email angleung@hku.hk
}

\begin{abstract}
Due to the lack of good infrastructure in the public estates, many older adults in urban areas are sedentary. The Health Enhancement and Pedometer-Determined Ambulatory (HEPA) program was developed to assist older adults with diabetes and/or hypertension to acquire walking exercise habits and to build social support, while engaged in regular physical activity. This study aimed to describe the HEPA program and to report changes in participants' walking capacity and body strength after 10-week walking sessions. A pre- and postintervention design was used. Pedometers were used to measure the number of steps taken per day before and after the 10-week intervention. Upper and lower body strength, lower body flexibility, and quality of life were assessed. A total of 205 older adults completed the program and all health assessments. After the 10-week intervention, the average number of steps per day increased by $36 \%$, from 6,591 to 8,934 . Lower body strength, upper body strength, and aerobic fitness increased significantly after 10 weeks, along with improvement in the 12-item Short Form Health Survey $\left(\mathrm{SF}^{\mathrm{TM}}-12\right)$ physical and mental health component summary scores. A social support network was built in the neighborhood, and the local environment was utilized to make walking possible and enjoyable.
\end{abstract}

Keywords: physical activity, Chinese, pedometers, social support, quality of life, older adults

\section{Introduction}

Evidence of the therapeutic effects of physical activity is well documented, as are the associated reductions in the risk of morbidity and chronic disease ${ }^{1-3}$ and the improvement in quality of life. ${ }^{4}$ Motivating sedentary persons to commit to physical activity is not an easy task. Encouraging walking can be the initial step in developing sedentary adults' commitment to other regular physical exercise modalities. ${ }^{5}$ Two systematic reviews showed that pedometers are useful tools for increasing older adult involvement in physical exercise and improving their health status. ${ }^{6}$ Innovative strategies have been developed to promote the use of pedometers to increase the daily steps of older adults with chronic illness. ${ }^{7}$ Pedometers can be used as motivational tools for sedentary persons, and setting goals in "steps" often is more effective in leading to an increase in walking than is goal setting in "minutes". 8

However, additional encouragement, such as social support, may be required to sustain increases in walking among older adults. ${ }^{8}$ The World Health Organization (WHO) has highlighted the importance of social networks in influencing health and thereby, the quality of life of older adults. ${ }^{9,10}$ A pilot study in the USA has shown that weekly 1-hour community group sessions facilitated an increase in the mean steps 
of sedentary older adults by $24 \%$ (equivalent to 2.5 miles) compared with their baseline measurements. ${ }^{5}$

The Hong Kong Special Administrative Region, located in the southern part of the People's Republic of China, is a densely populated city dominated by many high-rise buildings (with more than 7,600 high-rise buildings in 1,104 km² of land). ${ }^{11}$ It has been listed as the city with the most high-rise buildings in the world. ${ }^{11}$ Some parts of Hong Kong feature steep hills and narrow steps, which dictate that many older adults venture outdoors only when necessary and only if accompanied by a relative or friend. Many older adults live in the Central and Western districts of Hong Kong. There are two public housing estates in the Western District; Sai Wan Estate and Kwun Lung Estate, and many private independent buildings in the Central district. Due to the lack of infrastructure within each district, elderly residents seldom participate in regular physical activity and therefore become sedentary. To engage elderly residents in regular physical activity, the Health Enhancement and Pedometer-Determined Ambulatory (HEPA) program, combining the key components of a buddy system and pedometers, was developed.

\section{Purpose of the study}

The purpose of this study was to describe the features of the HEPA program and report its effectiveness at improving participants' health. The specific objectives of the study were to: 1) outline the key features of the HEPA program, to enable replication by other health educational practitioners in other communities; 2) assess and compare participants' physical activity level, in terms of number of steps per day before and after the intervention in the HEPA program; 3) assess and compare participants' physical fitness, in terms of body strength and aerobic fitness, before and after the intervention; and 4) assess and compare participants' health-related quality of life (HRQoL) before and after the intervention. We hypothesized that participants would take more steps than they did prior to participation in the HEPA program and that they would have improved physical fitness and HRQoL after participation in the HEPA program.

\section{The HEPA program}

This was a 2-year community-based health education program developed by a team of health and social service professionals, including two nursing faculty members, a family medicine practitioner, a physical fitness expert, and a social worker. At the planning stage of the HEPA program, an environmental assessment of the two public housing estates was completed. The team examined whether the facilities were available for physical activities and if so, their location, accessibility, and usage by residents. Four sets of public outdoor fitness equipment, designed for strengthening upper arm or thigh muscles, had been installed in an open area in one of the estates. However, many elderly residents did not know how to operate them, despite the instructions posted nearby, so these tools were seldom used. There were three community elderly centers in the neighborhood, and these were often used for social functions. Social activities, such as Chinese opera singing and chess games, were frequently offered, but the centers had never arranged any physical activity events, due to a lack of resources and expertise.

Social workers in these community elderly centers had good rapport and strong relations with the elderly residents as many were community center members. They made home visits to elders who were reluctant to participate in activities at the center and who stayed indoors most of the time at home.

The buildings were situated on a hillside, and the two public housing estates were composed of several blocks of "high rises" with long corridors; some of these were indoors, but most were outdoors. There was a community hall in the neighborhood, where large-scale activities were held. This hall was managed by the Leisure and Sports Department, and advanced booking was available for a reasonable charge.

The HEPA program activities took place at participants' own neighborhoods, utilizing local resources and facilities (open areas, indoor and outdoor long corridors within the estates, community social centers, and community hall). The program was comprised of ten health seminars, eleven health assessment sessions, five groups (each group offered ten weekly walking sessions), and four training workshops for buddy leaders. Buddy leaders were younger elderly residents in the two public housing estates, and they were trained to motivate and accompany the HEPA participants in the weekly walking sessions.

The health seminars addressed the importance of physical activity in diabetes management and were conducted by faculty from the School of Nursing and Active Health Clinic of the University of Hong Kong. These seminars were held at the community elderly center, community halls, and open areas at the two public housing estates. The seminars provided opportunities to introduce the HEPA program and recruit participants to the 10 weeks of weekly walking sessions and health assessment.

The walking sessions operated in small groups, and participants were divided into five groups. Each walking session lasted 60 minutes and usually began with a 10 -minute 
warm-up exercise led by a physical fitness officer and/or buddy leaders. The warm-up exercise was customized for older adults by the physical fitness officer, who had expertise in age-related physiological changes and limitations. These included marching in place for 1 to 2 minutes, squatting, shoulder flexion, and lateral bending exercises. After the warm-up exercises, buddy leaders led the group for a walk in the neighborhood. In consideration of the participants' walking capacity and the hilly environment, the project team identified several routes on the public estates that could be used on either sunny or rainy days. The walking sessions offered opportunities for participants to walk together and to discuss health issues and strategies in diabetes care. These sessions were expected to develop participants' self-efficacy (or belief that they could accomplish the goal) in doing exercise and to build community capacity for peer support for regular physical activities. Nursing students, project team members, and adult volunteers joined in the walks, whenever they were available.

A team of 82 buddy leaders was trained at four workshops. They were trained at a half-day workshop, conducted by a nurse and a physical fitness officer. The content of the workshop included basic first aid skills (action in the event of an accident during a walking session), group management, group walking safety measures, and concepts of social support and networking. These buddy leaders also served as role models in the neighborhood, encouraging sedentary older adults to undertake regular walks during nonscheduled walking periods. Each trained buddy leader was paired with five sedentary older adults, connecting with them via phone calls between sessions and accompanying them on walks. Pedometers were distributed to all participants and buddy leaders, who were encouraged to record their daily number of steps in logbooks. The project team collected the recordings in the logbook and pedometers at the end of the 10th week.

Health assessments were held at eleven half-day sessions in the community hall. The health assessment team was comprised of three nurses, three physical fitness officers, a trained postgraduate nursing student, and two social workers. In each session, 20-30 older adults participated in the health assessment, and all received a 1-hour health assessment, including evaluation of their self-efficacy for exercise, quality of life, blood pressure, blood tests (blood glucose test and total cholesterol test), upper and lower body strength assessment, lower body flexibility assessment, and aerobic fitness. To facilitate health assessment efficiency, eight stations were set up in the community hall so that eight older adults could be assessed for different parameters at the same time. Health assessments were conducted before the start of the 10-week walking sessions and 2 to 3 weeks after the last walking session. Health counseling was given to participants, based on the parameters of the health assessment just before they left the community hall. The preintervention assessment parameters measured the individual risk of undertaking exercise independently, and health counseling mainly focused on risk explanation and capacity building. The postintervention assessment parameters evaluated the effectiveness of the 10-week walks and reviewed individual changes of functional fitness after the intervention.

\section{Methods Design and subjects}

A nonexperimental pre- and postintervention design was adopted to evaluate the effectiveness of the 10 -week walking sessions. Persons who met the following criteria were eligible to participate in the 10 -week walking sessions: aged 60 or above; residing in the Central and Western District; diagnosed with hypertension and/or type 2 diabetes mellitus; able to ambulate independently; and sedentary. According to the American College of Sports Medicine, "sedentary" is defined as those who do not engage in moderate-intensity cardiorespiratory exercise training for $\geq 30$ minutes per day on $\geq 5$ days per week for a total of $\geq 150$ minutes per week, vigorous-intensity cardiorespiratory exercise training for $\geq 20$ minutes/day on $\geq 3$ days per week ( $\geq 75$ minutes per week), or a combination of moderate- and vigorous-intensity exercise to achieve a total energy expenditure of $\geq 500-1,000$ Metabolic Equivalent Task (MET) per minute per week. ${ }^{12}$ In addition, those advised by doctors to restrict physical activity were excluded from participating. All eligible participants were recruited from three elderly community centers.

Ethical approval for data collection was obtained from the Institutional Review Board of the University of Hong Kong/Hospital Authority Hong Kong West Cluster.

\section{Measures}

Functional fitness was measured, including upper body strength (arm curl strength), lower body strength (30-second sit-to-stand), aerobic endurance (6-minute walk test), and lower body flexibility (chair sit-to-reach). ${ }^{13,14}$ To measure arm curl strength, participants were asked to bend their forearms as many times as possible in 30 seconds while holding weights $(5$ $\mathrm{lbs}$ for women, $8 \mathrm{lbs}$ for men). To test lower body strength, participants were asked to sit in a chair and then stand up with arms folded across the chest. The number of full stands in 30 seconds was counted. To test aerobic endurance, participants were 
asked to walk as many rounds as possible in a standardized circle in 6 minutes. To test lower body flexibility, participants were asked to sit on the front part of a chair with legs extended and hands reaching towards the toes. The distance between the extended fingers and tip of the toe was measured. ${ }^{13,14}$ These measures were part of the Senior Fitness Test. ${ }^{13,14}$ Other clinical parameters were also taken, including body mass index (BMI), blood glucose, total cholesterol, body fat, and muscle mass, as well as demographic variables, including age, sex, education level, marital status, occupation, living status, and history of illnesses. The number of steps was measured using pedometers (SW-200 Digi-Walker ${ }^{\mathrm{TM}}$; New-Lifestyles Inc, Lees Summit, MO, USA). Participants were advised to wear the pedometers at waist level for 10 weeks ( 7 days per week). HRQoL was measured with the physical component and mental health component summary scores of the Chinese (Hong Kong) translation of the 12-item Short Form Health Survey ( $\mathrm{SF}^{\mathrm{TM}}$-12) (QualityMetric Inc, Lincoln, RI, USA). ${ }^{15}$ The SF-12 has been shown to be valid in the Hong Kong Chinese population. ${ }^{15}$ Self-efficacy in undertaking exercise was measured with the Self-efficacy for Exercise Scale (SEE). ${ }^{16}$ This eleven-item scale focused on individuals' confidence related to the ability to perform exercise when barriers exist. Approval for using this scale was obtained from its author (B Resnick), and this scale has been used in other previous studies. ${ }^{17}$ Participants were asked to circle the number most closely related to the confidence they had for exercising three times a week for 20 minutes if a particular barrier existed. Responses were measured on a eleven-point Likert scale ranging from $0=$ not confident to $10=$ very confident. Items were summed to produce a score ranging from 0 to 110 , with higher scores indicating higher levels of self-efficacy for exercise. The scale has reasonably good internal consistency, and its validity was assessed by confirmatory factor analysis. ${ }^{16,17}$ The internal consistency of the SEE in the current study was good (Cronbach's alpha $=0.838$ ). Comorbidity was measured by the Functional Comorbidity Index, an 18-item list of diagnoses that is used to classify adults into different levels of physical function and predict mortality. ${ }^{18}$

\section{Data analysis}

Participants' demographics were presented using descriptive statistics, including frequency and percentage for categorical variables, and mean and standard deviation (SD) for continuous variables. Intention-to-treat analysis was adopted to evaluate the effectiveness of the intervention. The assessment results of all participants were included in the analysis. For those who did not attend the postintervention assessment, the "last observation carried forward" method was employed to handle the missing data. Thus, the missing data in the postintervention assessment was replaced by the results of the preintervention assessment. The mean and SD of outcome measures, including functional fitness parameters, clinical parameters, quality of life measure, and self-efficacy for exercise, before and after the intervention were reported. The difference in these parameters was tested with paired-sample $t$-test. A 5\% significance level was adopted in this study.

\section{Results \\ Descriptive statistics}

The concept of regular walking in chronic illness management was explained to 932 persons in the health seminars, and 241 persons were recruited to join the HEPA program. Among these, 13 persons joined the trial run of the program, which assessed the flow of the planned strategies. A total of 205 participants agreed to participate in the HEPA activities (Figure 1). Table 1 shows the demographic characteristics of the subjects. Most participants (79\%) were women, with a mean age of 74.2 (SD 7.2) years, and $43.3 \%$ were single, divorced or widowed, $57 \%$ were married. Approximately $66 \%$ were educated at primary level or below. About 52.7\% were retired, and $47.3 \%$ were housewives. Approximately one-half of the participants had cataracts and hypertension. One-fifth had osteoporosis or diabetes. The Functional Comorbidity Index scores of this sample ranged from 0 to 5, with the mean of this index being 2.17 (SD 0.98). One-quarter of the participants had a mean comorbidity score of 1 , while one-third demonstrated a score $\geq 3$.

A total of $179(87.3 \%)$ participants completed the 10 -week intervention and postintervention assessment and were thus considered completers. There was no significant difference between completers $(n=179)$ and noncompleters $(n=26)$ in terms of age, sex, marital status, educational attainment, employment status, functional comorbidity score, functional fitness parameters, clinical parameters, HRQoL, and self-efficacy for exercise. The only significant difference between the two groups was their attendance in the 10-week intervention. Noncompleters had significantly lower attendance than did the completers $(33.8 \%$ vs $78.7 \%)$. Noncompleters were busy and unable to attend the weekly meetings and/or the postintervention assessment. Table 2 shows the comparisons between completers and noncompleters.

\section{Walking frequency and physical fitness}

The average numbers of walking steps increased by $36 \%$, from 6,591 steps in week 1 to 8,934 steps in week 10 $(P=0.005)$. Table 3 shows the change of functional fitness 


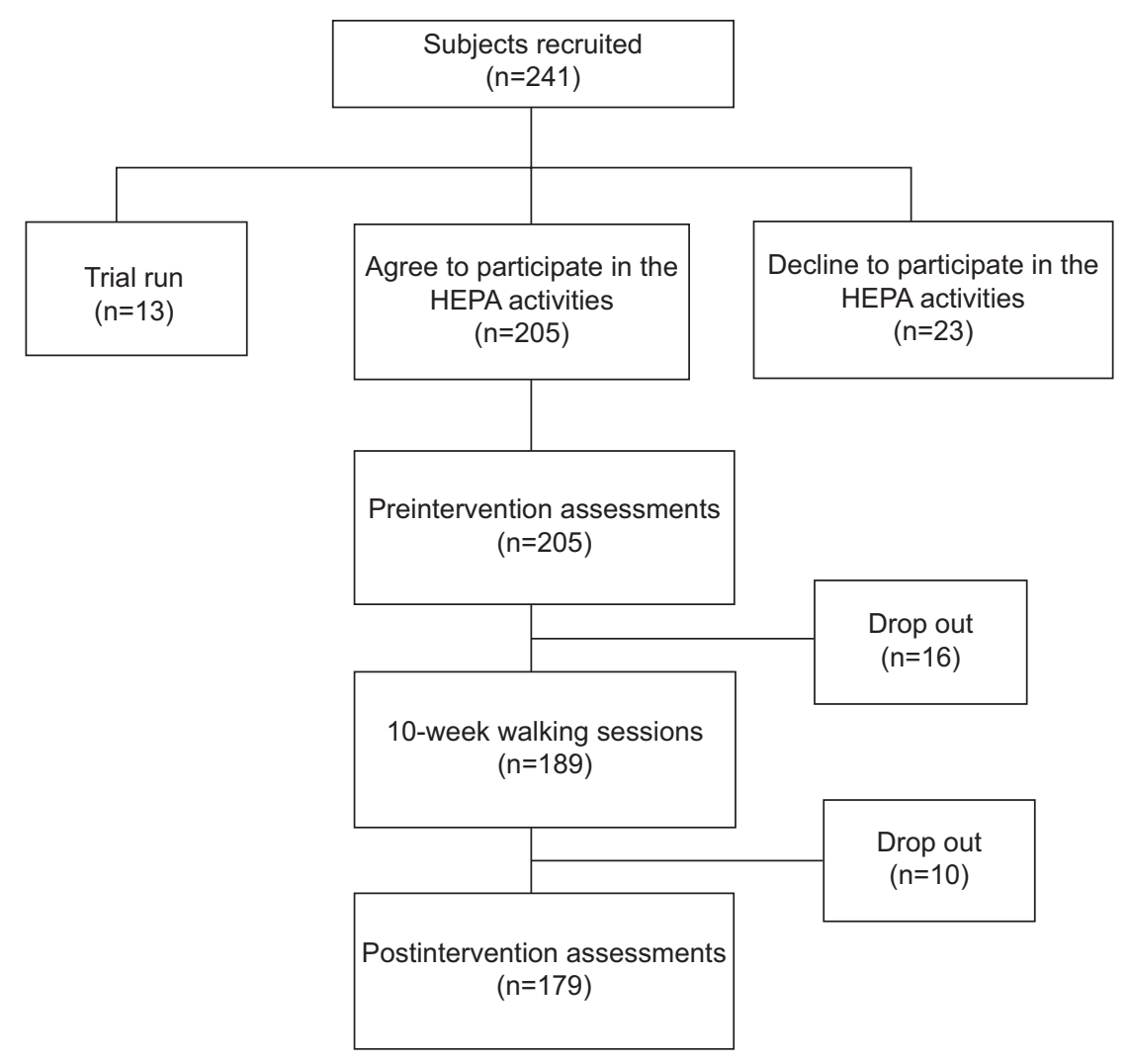

Figure I Flowchart showing the number of subjects in the HEPA program.

Abbreviation: HEPA, Health Enhancement and Pedometer-Determined Ambulatory.

parameters after the 10 -week intervention. Following the intervention, there was a significant increase in lower body strength (mean $[\mathrm{SD}]=12.09$ [3.95] versus 13.60 [4.45]) ( $t=6.28, P<0.001$ ); upper body strength (mean $\mathrm{SD}=13.06$ [3.61] versus 14.21 [3.99]) $(t=5.10, P<0.001)$; and 6-minute walk test (mean $\mathrm{SD}=421.98$ [88.22] versus 440.16 [87.82]) ( $t=6.03, P<0.001$ ) (Table 3). Both the physical health component summary score (mean $\mathrm{SD}=44.32$ [9.77] versus 47.18 [8.93]) $(t=4.17, P<0.001)$ and mental health component summary score (mean $\mathrm{SD}=53.25$ [9.65] versus 55.36 [8.34]) $(t=2.82, P<0.01)$ of the SF-12 had significantly improved after the 10-week intervention. However, there was no significant change in lower body flexibility, BMI, total cholesterol, blood glucose, blood pressure, body fat, muscle mass, or self-efficacy for exercise.

Among all the participants, eleven requested the walks be continued for another 4 weeks. After the 14th week, they participated in health assessment. Lower body strength (mean difference $[\mathrm{MD}]=+14.00)(P<0.001)$ and upper body strength ( $\mathrm{MD}=+23.36)(P<0.001)$ improved significantly when compared to the baseline measurements. Similar significant changes were observed in these two variables compared to the first follow up at the 10th week.

\section{Discussion}

The HEPA program was successfully implemented, and the aims to change sedentary older adults' physical exercise behavior and raise their walking level were met. Participants' mean daily steps increased significantly when compared with their baseline, and they reached the recommended number of steps $(8,000$ steps per day) for community-dwelling older adults, which achieves the same level of physical activity benefit as that with 10,000 steps in adults. ${ }^{19}$ As recommended by the National Institute on Aging of America, older adults can significantly benefit from 30-minutes of moderate-intensity endurance activity on most or all days of the week. ${ }^{20}$ It is important to support moderate-intensity endurance physical activity; however, implementing this practice in a highly densely populated city deserves welldesigned strategies.

The current project demonstrated that within the studied neighborhoods, pedometers and an exercise buddy scheme could increase Chinese older adults' walking level. The buddy leaders implemented what they learned at the training workshops and supported sedentary older adults with telephone reminders and by being a companion in the weekly walking sessions. These practices illustrate a way to translate 
Table I Demographics of subjects in the HEPA program

\begin{tabular}{|c|c|c|}
\hline & $\mathbf{n}$ & $\%$ \\
\hline \multicolumn{3}{|l|}{ Sex } \\
\hline Female & 162 & 79.0 \\
\hline Age (mean \pm SD) & \multicolumn{2}{|c|}{$74.2 \pm 7.2$} \\
\hline $60-69$ yrs & 56 & 27.3 \\
\hline $70-79$ yrs & 100 & 48.8 \\
\hline $80-89$ yrs & 43 & 21.0 \\
\hline$\geq 90 \mathrm{yrs}$ & 6 & 2.9 \\
\hline \multicolumn{3}{|l|}{ Marital status } \\
\hline Married & 115 & 56.7 \\
\hline Single/Widows/Divorced & 88 & 43.3 \\
\hline \multicolumn{3}{|l|}{ Education attainment } \\
\hline No formal education & 43 & 21.2 \\
\hline Primary & 91 & 44.8 \\
\hline Secondary or above & 72 & 34.0 \\
\hline \multicolumn{3}{|l|}{ Employment status } \\
\hline Retired & 107 & 52.7 \\
\hline Housewife & 96 & 47.3 \\
\hline \multicolumn{3}{|l|}{ Chronic illness ${ }^{a}$} \\
\hline Cataract & III & 54.1 \\
\hline Hypertension & 104 & 50.7 \\
\hline Osteoporosis & 46 & 22.4 \\
\hline Diabetes & 39 & 19.0 \\
\hline Heart disease & 22 & 10.7 \\
\hline Functional comorbidity index (mean $\pm S D)$ & \multicolumn{2}{|c|}{$2.17 \pm 0.98$} \\
\hline I & 53 & 25.9 \\
\hline 2 & 91 & 44.4 \\
\hline 3 or above & 61 & 29.7 \\
\hline
\end{tabular}

Notes: $\mathrm{N}=205$. aSome participants had more than one type of illness. Abbreviations: HEPA, Health Enhancement and Pedometer-determined Ambulatory; SD, standard deviation.

knowledge into practice in the community. ${ }^{21}$ In addition to the empirical findings, we reviewed the success of the HEPA program with respect to three aspects; execution, observation, and benefits of the completed project.

\section{Execution}

The HEPA program was an interdisciplinary collaboration. Implementation would not have been possible without the support of many parties, including the Leisure and Cultural Services Department, Hong Kong Housing Society, various university departments, and the elderly community centers. Each party contributed its expertise in making this program a success. For example, social workers in the elderly community centers motivated members to attend the health seminars, nursing faculty taught at the health seminars, and nurses and health-and-fitness officers conducted the health and functional fitness assessments and trained the buddy leaders to facilitate warm-up exercises. One of the crucial elements of the program was to identify safe walking tracks in the neighborhood. Government departments offered convenient venues for conducting health assessments and walks.
The trial run held in early 2010 with 13 participants was a crucial step in the program. This provided the project team with information and opportunities to review procedures and recruitment strategies.

\section{Observation}

We witnessed older adults' active participation during the walking sessions, their motivation in attending health assessments, and their enthusiasm to understand the changes in health parameters after the 10-week intervention. Some relatives accompanied participants to the health counselling sessions. Observation was also conducted in the walking sessions, during which many participants expressed satisfaction with the HEPA program, their appreciation of the customized warm-up exercises, and the identified safe walking tracks. The completion rate of the 10 -week walking sessions was high.

\section{Benefits of the completed project}

The HEPA program was not only beneficial to participants but also, to volunteers and staff at the elderly centers, who gained experience operating an evidence-based community project, with support from various departments. Through this project, knowledge was transferred from academics to practitioners who worked daily with community-dwelling older adults. The knowledge transferred can be listed as, but not limited to, the relationship between physical activity and chronic illness management, use of pedometers and logbook as motivators to change health behavior, interpretation of some health parameters, and first aids skills in managing heat stroke. By the end of the HEPA program, staff at the community centers demonstrated confidence in facilitating similar programs in their own capacity and with their own resources.

The HEPA program successfully cultivated districtbased social networks and a safe environment for regular walking, for older adults in a densely populated city. One of the key features of the HEPA program was the training of volunteers as "buddy leaders" in the community. Under this buddy scheme, older adults were able to enjoy social support in their neighborhood. Additionally, facilities in the neighborhood were used for walking exercises, health assessment, volunteer training, and the closing ceremony. Easy access to the activity venues enhanced participation. Social support networks and physical environment are two of the determinants of health. ${ }^{9}$ It is important to consider these factors when planning and implementing health promotion programs for community-dwelling older adults. 
Table 2 Comparison between completers and noncompleters of all activities in the HEPA program

\begin{tabular}{|c|c|c|c|c|c|}
\hline & \multicolumn{2}{|c|}{ Noncompleters $(n=26)$} & \multicolumn{2}{|c|}{ Completers $(n=179)$} & \multirow[t]{2}{*}{$P$-value } \\
\hline & $\mathbf{N}$ & $\%$ & $\mathbf{N}$ & $\%$ & \\
\hline \multicolumn{6}{|l|}{ Demographics } \\
\hline Sex & & & & & 0.798 \\
\hline Male & 6 & 23.1 & 37 & 20.7 & \\
\hline Female & 20 & 76.9 & 142 & 79.3 & \\
\hline Age (mean, SD) & 73.0 & 8.02 & 74.4 & 7.08 & 0.336 \\
\hline $60-69$ yrs & 11 & 42.3 & 45 & 25.1 & 0.205 \\
\hline $70-79$ yrs & 8 & 30.8 & 92 & 51.4 & \\
\hline $80-89$ yrs & 6 & 23.1 & 37 & 20.7 & \\
\hline$\geq 90 \mathrm{yrs}$ & I & 3.8 & 5 & 2.8 & \\
\hline Marital status & & & & & 0.400 \\
\hline Married & 17 & 65.4 & 98 & 55.4 & \\
\hline Single/Widows/Divorced & 9 & 34.6 & 79 & 44.6 & \\
\hline Education attainment & & & & & 0.366 \\
\hline No formal education & 4 & 15.4 & 39 & 22.0 & \\
\hline Primary & 15 & 57.7 & 76 & 42.9 & \\
\hline Secondary or above & 7 & 26.9 & 62 & 35.0 & \\
\hline Employment status & & & & & 0.208 \\
\hline Retired & 17 & 65.4 & 90 & 50.8 & \\
\hline Housewife & 9 & 34.6 & 87 & 49.2 & \\
\hline \multicolumn{6}{|l|}{ Functional comorbidity index } \\
\hline I & 11 & 42.3 & 42 & 23.5 & 0.107 \\
\hline 2 & 10 & 38.5 & 81 & 45.3 & \\
\hline \multirow[t]{2}{*}{3 or above } & 5 & 19.2 & 56 & 31.3 & \\
\hline & Mean & SD & Mean & SD & \\
\hline \multicolumn{6}{|l|}{ Functional fitness parameters } \\
\hline Arm curl test (repetitions) & 13.4 & 3.31 & 13.0 & 3.65 & 0.588 \\
\hline 30-second sit-to-stand (repetitions) & 12.7 & 3.41 & 12.0 & 4.02 & 0.391 \\
\hline 6-minute walk test $(\mathrm{m})$ & 461.6 & 85.5 & 416.1 & 87.3 & 0.014 \\
\hline Chair sit-and-reach (cm) & 1.10 & 8.55 & 2.7 & 10.6 & 0.467 \\
\hline \multicolumn{6}{|l|}{ Clinical parameters } \\
\hline Body mass index $\left(\mathrm{kg} / \mathrm{m}^{2}\right)$ & 23.1 & 3.37 & 24.3 & 3.97 & 0.159 \\
\hline Total cholesterol (mg/dL) & 4.67 & 1.01 & 4.71 & 0.91 & 0.842 \\
\hline Blood glucose (mmol/L) & 8.12 & 8.38 & 6.18 & 1.88 & 0.250 \\
\hline Body fat (\%) & 29.9 & 7.79 & 32.1 & 8.40 & 0.194 \\
\hline Muscle mass (\%) & 36.9 & 6.04 & 35.6 & 6.13 & 0.288 \\
\hline \multicolumn{6}{|c|}{ Health-related quality of life (measured by SF-I2) } \\
\hline Physical health (PCS score) & 45.4 & 8.5 & 44.2 & 10.0 & 0.555 \\
\hline Mental health (MCS score) & 49.8 & 11.8 & 53.7 & 9.2 & 0.052 \\
\hline Self-efficacy for exercise & 4.02 & 0.84 & 4.13 & 0.75 & 0.483 \\
\hline Attendance (\%) & 33.8 & & 78.7 & & $<0.001$ \\
\hline
\end{tabular}

Abbreviations: HEPA, Health Enhancement and Pedometer-Determined Ambulatory; SD, standard deviation; PCS score, physical health component summary score; MCS score, mental health component summary score.

The use of pedometers in the HEPA program was a challenge to the older adults, particularly those with low educational levels and limited health literacy. Participants were initially hesitant about using the pedometers because of their concerns about their operation as this was unfamiliar technology. Everyday technology can cause stress to older adults, so it was important to develop their self-efficacy for using technology. ${ }^{22}$ The project team therefore addressed this issue by providing individualized training and diagrams to illustrate how to wear the pedometers correctly. Participants were also encouraged to call the project coordinator if there were any problems using the pedometer. A previous study found that pedometer use and step-recording diaries could only instill a short-term effect (lasting 2 weeks) on physical activity, among sedentary older adults. ${ }^{23}$ Therefore, the project team decided to adopt multiple strategies (pedometer, step-recording diary, buddy leaders' support scheme, and scheduled walking sessions) in the HEPA program. This was aimed at developing and maintaining group dynamics, and engaging participants in regular physical activity for up to 10 weeks.

Although there was no change in clinical parameters (such as blood glucose or total cholesterol) after the 10-week 
Table 3 Results of health assessment before and after the 10-week intervention

\begin{tabular}{|c|c|c|c|c|c|c|}
\hline & & Mean & SD & Difference (post-pre) & $t$ & $P$-value \\
\hline \multicolumn{7}{|l|}{ Functional fitness parameters } \\
\hline \multirow[t]{2}{*}{ Arm curl test (repetitions) } & Pre & 13.06 & 3.61 & 1.14 & 5.10 & $<0.001$ \\
\hline & Post & $|4.2|$ & 3.99 & & & \\
\hline \multirow[t]{2}{*}{ 30-second sit-to-stand (repetitions) } & Pre & 12.09 & 3.95 & 1.51 & 6.28 & $<0.001$ \\
\hline & Post & 13.60 & 4.45 & & & \\
\hline \multirow[t]{2}{*}{ 6-minute walk test $(\mathrm{m})$} & Pre & 421.98 & 88.22 & 18.18 & 6.03 & $<0.001$ \\
\hline & Post & 440.16 & 87.82 & & & \\
\hline \multirow[t]{2}{*}{ Chair sit-and-reach (cm) } & Pre & 2.48 & 10.35 & 0.83 & 1.54 & 0.125 \\
\hline & Post & 3.30 & 9.30 & & & \\
\hline \multicolumn{7}{|l|}{ Clinical parameters } \\
\hline \multirow[t]{2}{*}{ Body mass index $\left(\mathrm{kg} / \mathrm{m}^{2}\right)$} & Pre & 24.11 & 3.91 & -0.10 & -0.84 & 0.405 \\
\hline & Post & 24.01 & 3.71 & & & \\
\hline \multirow[t]{2}{*}{ Total cholesterol (mg/dL) } & Pre & 4.70 & 0.92 & -0.05 & -1.05 & 0.294 \\
\hline & Post & 4.65 & 0.95 & & & \\
\hline \multirow[t]{2}{*}{ Blood glucose (mmol/L) } & Pre & 6.43 & 3.49 & 0.21 & 0.71 & $0.48 \mathrm{I}$ \\
\hline & Post & 6.64 & 5.01 & & & \\
\hline \multirow[t]{2}{*}{ Body fat (\%) } & Pre & 31.84 & 8.34 & 0.04 & 0.27 & 0.791 \\
\hline & Post & 31.88 & 8.34 & & & \\
\hline \multirow[t]{2}{*}{ Muscle mass (\%) } & Pre & 35.74 & 6.12 & 0.10 & 0.51 & 0.608 \\
\hline & Post & 35.84 & 5.52 & & & \\
\hline \multicolumn{7}{|l|}{ Health-related quality of life } \\
\hline \multirow[t]{2}{*}{ Physical health (PCS score) } & Pre & 44.32 & 9.77 & 2.86 & 4.17 & $<0.001$ \\
\hline & Post & 47.18 & 8.93 & & & \\
\hline \multirow[t]{2}{*}{ Mental health (MCS score) } & Pre & 53.25 & 9.65 & 2.11 & 2.82 & 0.005 \\
\hline & Post & 55.36 & 8.34 & & & \\
\hline \multirow[t]{2}{*}{ Self-efficacy for exercise } & Pre & 4.15 & 0.72 & 0.00 & 0.03 & 0.977 \\
\hline & Post & 4.15 & 0.76 & & & \\
\hline
\end{tabular}

Note: $\mathrm{N}=205$.

Abbreviations: SD, standard deviation; PCS score, physical health component summary score; MCS score, mental health component summary score.

intervention, the study was an exemplar demonstration for encouraging sedentary older adults with diabetes and/or hypertension to undertake physical activity. In fact, level of physical activity should be targeted as a primary outcome in community-based programs, while changes in blood glucose levels might not be significant. ${ }^{24}$ However, it is worth noting that participants' physical and mental health significantly improved after the 10-week intervention. This finding echoes that of a 6-month community-based walking study in the neighbourhood, ${ }^{23}$ which also showed improvement of quality of life among the participants. Our study suggested that neighborhood walking affected participants' quality of life, and such effects can be observed in a short period of 10 weeks.

\section{Study limitations}

Several study limitations should be acknowledged. Firstly, the pre- and postintervention design only allowed for preliminary comparison of the variables of interest, and it is possible that some measures may have been influenced by a learning effect of repeated measurements. Therefore, the actual effectiveness of the HEPA program should be further investigated. Randomized controlled trials are needed to test the effectiveness of the HEPA program on participants' physical activity levels and other health outcomes. Secondly, self-efficacy for exercise is a self-reported measure. Respondents, particularly Chinese respondents who adhere to Chinese culture and the concept of saving face, may provide socially favored or positive answers to the questions. Although the Chinese version of the SEE scale has been validated, ${ }^{25}$ the sensitivity of this scale to Chinese culture has not been investigated. This should be assessed in a future study. Thirdly, our study mainly recruited older adults with hypertension and/or diabetes. The findings may not be generalized to patients with other chronic illnesses. Fourthly, the outcome changes were observed within a short period of time after the intervention. Therefore we are uncertain whether the intervention has any long-term effect on the participants' health status and healthy habits. Only a small number of participants were willing to be followed up 4 weeks after the intervention. A study with a larger sample and using a longitudinal design should be considered in the future. 


\section{Conclusion}

The HEPA program was shown to increase the participants' mean daily steps, upper and lower body strength, aerobic endurance, and HRQoL. Although there was no improvement in blood glucose or blood pressure, HEPA serves as a good example for promoting a healthy lifestyle among community-dwelling older adults. Through the HEPA program, attention has been drawn to the importance of social support networks and the local environment in health maintenance. Volunteers were trained to be buddy leaders in the community, and this built a network to support older adults in regular physical activity. Walking routes were identified, and guidelines and training materials for exercise buddies were set up. These activities can be transferred to the elderly community centers, where programs like this can be sustained with minimal operational cost. The HEPA program also demonstrated how knowledge could be transferred from academics to practitioners and lay persons. The protocol for the HEPA program was developed with reference to empirical evidence, with contributions from the faculty, nongovernment organizations, and government departments. Our findings provide empirical evidence of a knowledge transfer program.

\section{Author contributions}

AYM Leung contributed to the study design, application for ethical approval, funding application, data analysis, interpretation of the findings, and drafting of the manuscript. MKT Cheung contributed to data collection, data analysis, and drafting of the manuscript. MA Tse contributed to study design, application for ethical approval, funding application, data collection, interpretation of the findings, and revision of the manuscript. BJ Lancaster contributed to study design, funding application, and revision of the manuscript. CLK Lam contributed to funding application, interpretation of the findings, and revision of the manuscript.

\section{Acknowledgments}

We wish to acknowledge the invaluable contribution of the participants and voluntary team leaders. Special thanks to Ms Ka Yan Kwok, Mr Henri Chan, Ms Kimmy Ma, Ms Dennise Tsang, Mr Kenneth Liang, Ms Chi Wah Lau, Mr Glen Joe, Ms Karen Cheung, and Ms Chak Ho Yee for their kind support and assistance during health assessments, subject recruitment, and the walking sessions. We would also like to thank the Hong Kong Sheng Kung Hui (HKSKH) Western District Elderly Community Center, HKSKH St Luke's Settlement Neighbourhood Elderly Center, and HKSKH St Matthew's
Neighbourhood Elderly Center for their kind support in coordinating the project. We especially thank the Health Care Promotion Fund of the Health and Welfare Bureau for funding this project. Without the kind support from all the organizations, volunteers, and participants, the implementation of this project would not be possible. Gratitude also goes to Ms Lisa Wong for technical writing support.

This work was supported by the Health Care Promotion Fund-Seed Funding Scheme 2008/2009, Health and Welfare Bureau, the Government of Hong Kong Special Administrative Region, People's Republic of China.

\section{Disclosure}

The authors report no conflicts of interest in this work.

\section{References}

1. Bean JF, Vora A, Frontera WR. Benefits of exercise for communitydwelling older adults. Arch Phys Med Rehabil. 2004;85(7 Suppl 3) S31-S42.

2. Talbot LA, Morrell CH, Metter EJ, Fleg JL. Comparison of cardiorespiratory fitness versus leisure time physical activity as predictors of coronary events in men aged $<$ or $=65$ years and $>65$ years. $A m J$ Cardiol. 2002;89(10):1187-1192.

3. Tudor-Locke C, Bassett DR. How many steps/day are enough? Preliminary pedometer indices for public health. Sports Med. 2004; 34(1):1-8.

4. Morrow JR, Jackson AW, Bazzarre TL, Milne D, Blair SN. A oneyear follow-up to physical activity and health. A report of the Surgeon General. Am J Prev Med. 1999;17(1):24-30.

5. Sarkisian CA, Prohaska TR, Davis C, Weiner B. Pilot test of an attribution retraining intervention to raise walking levels in sedentary older adults. J Am Geriatr Soc. 2007;55(11):1842-1846.

6. Bravata DM, Smith-Spangler C, Sundaram V, et al. Using pedometers to increase physical activity and improve health: a systematic review. JAMA. 2007;298(19):2296-2304.

7. Farmer BC, Croteau KA, Richeson NE, Jones DB. Using pedometers as a strategy to increase the daily steps of older adults with chronic illness: from research to practice. Home Healthc Nurse. 2006;24(7):449-456.

8. Baker G, Mutrie N, Lowry R. Using pedometers as motivational tools: are goals set in steps more effective than goals set in minutes for increasing walking? Int J Health Promot Educ. 2008;46(1):21-26.

9. who.int [homepage on the Internet]. Health Impact Assessment (HIA) The determinants of health. World Health Organization; 2014 [cited March 7, 2014]. Available from: http:/www.who.int/hia/evidence/doh/ en/. Accessed June 15, 2014.

10. World Health Organization (WHO) Regional Office for Europe. Health 2020 Policy Framework and Strategy. Copenhagen: World Health Organization (WHO) Region Office for Europe; 2012. Available from: http://www.euro.who.int/_data/assets/pdf_file/0020/170093/ RC62wd08-Eng.pdf. Access March 07, 2014.

11. twistedsifter.com [homepage on the Internet]. Top 25 cities in the world with the most high-rise buildings. Twisted Sifter; 2011 [cited April 14, 2014]. Available from: http://twistedsifter.com/2011/11/top-25-citieswith-most-high-rise-buildings/. Accessed June 15, 2014.

12. Garber CE, Blissmer B, Deschenes MR, et al; American College of Sports Medicine. American College of Sports Medicine position stand. Quantity and quality of exercise for developing and maintaining cardiorespiratory, musculoskeletal, and neuromotor fitness in apparently healthy adults: guidance for prescribing exercise. Med Sci Sports Exerc. 2011;43(7):1334-1359. 
13. Chen HT, Lin CH, Yu LH. Normative physical fitness scores for community-dwelling older adults. J Nurs Res. 2009;17(1):30-41.

14. Brovold T, Skelton DA, Bergland A. Older adults recently discharged from the hospital: effect of aerobic interval exercise on health-related quality of life, physical fitness, and physical activity. J Am Geriatr Soc. 2013;61(9):1580-1585.

15. Lam CL, Tse EY, Gandek B. Is the standard SF-12 health survey valid and equivalent for a Chinese population? Qual Life Res. 2005;14(2): 539-547.

16. Resnick B, Jenkins LS. Testing the reliability and validity of the SelfEfficacy for Exercise scale. Nurs Res. 2000;49(3):154-159.

17. Krisko-Hagel KA. Predictors for Participation in a Cardiac Rehabilitation Program Feasibility Study [PhD dissertation]. Minneapolis, MN: University of Minnesota; 2009. Available from: http://conservancy. umn.edu/bitstream/58442/1/KriskoHagel_umn_0130E_10908.pdf. Accessed April 14, 2014.

18. Groll DL, To T, Bombardier C, Wright JG. The development of a comorbidity index with physical function as the outcome. J Clin Epidemiol. 2005;58(6):595-602.

19. Ewald B, Attia J, McElduff P. How many steps are enough? Doseresponse curves for pedometer steps and multiple health markers in a community-based sample of older Australians. J Phys Act Health. 2014;11(3):509-518.
20. National Institute of Health, National Institute on Aging. Exercise and Physical Activity: Your Everyday Guide from the National Institute on Aging. Bethesda, MD: National Institute of Health, National Institute on Aging; 2009. Available from: http://www.nia.nih.gov/sites/default/files/ nia_exercise_and_physical_activity.pdf. Accessed April 14, 2014.

21. Hooker SP, Seavey W, Weidmer CE, et al. The California active aging community grant program: translating science into practice to promote physical activity in older adults. Ann Behav Med. 2005;29(3):155-165.

22. Yagil D, Cohen M, Beer JD. Older adults' coping with the stress involved in the use of everyday technologies. J Appl Gerontol. Epub 2013 Dec 30

23. Fisher KJ, Li F. A community-based walking trial to improve neighborhood quality of life in older adults: a multilevel analysis. Ann Behav Med. 2004;28(3):186-194.

24. Batik O, Phelan EA, Walwick JA, Wang G, LoGerfo JP. Translating a community-based motivational support program to increase physical activity among older adults with diabetes at community clinics: a pilot study of Physical Activity for a Lifetime of Success (PALS). Prev Chronic Dis. 2008;5(1):A18.

25. Lee LL, Perng SJ, Ho CC, Hsu HM, Lau SC, Arthur A. A preliminary reliability and validity study of the Chinese version of the self-efficacy for exercise scale for older adults. Int J Nurs Stud. 2009;46(2): 230-238.
Clinical Interventions in Aging

\section{Publish your work in this journal}

Clinical Interventions in Aging is an international, peer-reviewed journal focusing on evidence-based reports on the value or lack thereof of treatments intended to prevent or delay the onset of maladaptive correlates of aging in human beings. This journal is indexed on PubMed Central, MedLine,

\section{Dovepress}

CAS, Scopus and the Elsevier Bibliographic databases. The manuscript management system is completely online and includes a very quick and fair peer-review system, which is all easy to use. Visit http://www.dovepress. com/testimonials.php to read real quotes from published authors. 